\title{
Dampak Sosial Ekonomi dan Lingkungan Pengolahan Kopi Robusta BUMDes Tugu Sari, Desa Pajahan, Kecamatan Pupuan, Kabupaten Tabanan
}

\author{
I PUTU EDI SWASTAWAN,I MADE SUDARMA, I NYOMAN GEDE USTRIYANA
}

\author{
Program Studi Agribisnis, Fakultas Pertanian, Universitas Udayana \\ Jalan P.B. Sudirman-Denpasar, 80232 \\ Email: edi.swastawan99@gmail.com \\ sudarmaimade@yahoo.com
}

\begin{abstract}
The Socio-economic and Environmental Impacts of the Robusta Coffee Processed by the Tugu Sari Village-Owned Enterprise 'BUMDes', Pajahan Village, Pupuan District, Tabanan Regency
\end{abstract}

The Tugu Sari Village-Owned Enterprise 'Badan Usaha Milik Desa (BUMDes)' is a Robusta coffee processing enterprise run by the village. It was established to support the Village's Original Income 'Pendapatan Asli Daerah (PAD)', improve the local people's prosperity, serve the local people, improve the management of the village's assets, and maximize and sustain the potential which the village, as the one where Robusta coffee is produced, has. This current study was intended to identify the impact of the existence of the Tugu Sari BUMDes, Pajahan Village, based on the sustainable development system. Three impacts were explored in the current study. They are the social, economic and environmental impacts. The social and environmental impacts on the existence of the BUMDes were measured through the local people's perception, and the economic impact was measured based on the score obtained using the Keynesian economic impact. The result of the study shows that the local people's perception of the social impact of the BUMDes was good. The economic impact was that the existence of the BUMDes could contribute to the local people's economy based on the score obtained through the Keynesian multiplier effect, namely 1.35 . The local people's perception was not good environmentally, as the noise produced by the coffee processing machine disturbed the learning process at Elementary School 2 Pajahan. Therefore, it is suggested that the coffee processing machine should be relocated, so it would not disturb the learning process at Elementary School 2 Pajahan.

Keywords: BUMDes and impact

\section{Pendahuluan \\ 1.1 Latar Belakang}

Secara umum konsep pertanian berkelanjutan terdiri dari aspek ekonomi, sosial dan lingkungan. Budiasa (2011) mengemukakan bahwa pertanian berkelanjutan harus mengupayakan pencapaian tujuan ekonomi (efisiensi dalam bentuk peningkatan pendapatan), tujuan sosial (distributif dalam bentuk kemampuan memperkecil kesenjangan antara si kaya dengan si miskin) dan tujuan lingkungan (tetap mendukung 
kesejahteraan generasi mendatang). Pembangunan berkelanjutan penting diterapkan pada sektor pertanian. Keberlanjutan sektor pertanian tidak hanya menekankan konservasi sumberdaya alam saja melainkan juga peningkatan produksi dan pendapatan masyarakat jangka panjang.

Potensi pertanian Indonesia memegang peran penting dalam pembangunan nasional. Berdasarkan data Kemenperin (2016) nilai ekspor sektor pertanian mengalami kenaikan dari 3.597.679,8 US\$ pada tahun 2012 menjadi 3.725.342,7 US\$ pada tahun 2015 dengan persentase peranan dalam kegiatan ekspor sejumlah 2,38\%. Salah satu komoditi yang berkontribusi adalah komoditi kopi dengan nilai rata-rata pertumbuhan volume ekspor dari tahun 1980-2015 mencapai 4,39\% per tahun (Kementan, 2016).

Implementasi pengolahan pasca panen kopi tidak terbatas pada pengembangan skala industri besar. Pengembangan pengolahan kopi juga dapat direalisasikan secara kooperatif di pedesaan. Usaha memaksimalkan kegiatan industri pengolahan kopi tersebut, perlu dibentuk paradigma baru secara kolektif, kolegial dan kooperatif menuju pemberdayaan masyarakat berbasis pembangunan pertanian berkelanjutan.Slamet dalam Sadono (2008) mengemukakan sembilan paradigma pemberdayaan petani. Sembilan paradigma tersebut yaitu 1) jasa informasi, 2) lokalitas fasilitas, 3) berorientasi agribisnis, 4) pendekatan kelompok dari bawah (buttom up), 5) fokus terhadap kepentingan petani, 6) pendekatan humanistik egaliter, 7) profesionalisme, 8) akuntabilitas dan 9) memuaskan petani.

Nasrul (2012) mengemukakan bahwa pengembangan masyarakat petani dapat dilaksanakan melalui kelembagaan pertanian dalam upaya pemberdayaan terencana yang dilakukan secara sadar dan sungguh-sungguh melalui usaha bersama petani untuk memperbaiki keragaman sistem perekonomian masyarakat pedesaan. Suriadiasastra (2008) menyatakan kelembagaan memerlukan strategi pendekatan yang mampu memfasilitasi aspirasi sosial-budaya dan aspirasi teknis petani serta lembaga pembangunan pertanian setempat lainnya.Keberadaan kelembagaan hendaknya ada pada wilayah terdekat dari stakeholder (petani) agar dapat menyesuaikan keadaan sosial-budaya dan aspirasi teknis.

Konsep tersebut yang diterapkan oleh BUMDes Tugu Sari Pajahan sebagai badan yang dikelola dalam upaya pengolahan pasca panen kopi robusta. Tujuan berdirinya lembaga ini untuk memperkuat PAD (Pendapatan Asli Desa), memajukan perekonomian, meningkatkan kesejahtraan masyarakat, memberikan pelayanan masyarakat, meningkatkan pengelolaan aset-aset desa dan mengoptimalkan potensi kewilayahan sebagai penghasil kopi robusta secara berkelanjutan. Pengembangan BUMDes Tugu Sari Pajahan seharusnya mampu memberikan dampak positif terhadap masyarakat secara berkelanjutan dari aspek sosial ekonomi dan lingkungan. Kurun waktu dua tahun berdiri, belum pernah dilakukan kajian untuk mengetahui sejauh mana dampak BUMDes tersebut. Penelitian ini penting dilakukan guna mengetahui dampak BUMDes pada masyarakat Desa Pajahan berdasarkan konsep pertanian berkelanjutan. 


\subsection{Rumusan Masalah}

1. Bagaimana persepsi masyarakat terhadap dampak sosial pengolahan kopi robusta BUMDes Tugu Sari di Desa Pajahan.

2. Bagaimana dampak ekonomi pengolahan kopi robusta BUMDes Tugu Sari di Desa Pajahan.

3. Bagaimana persepsi masyarakat terhadap dampak lingkungan dari pengolahan kopi robusta BUMDes Tugu Sari di Desa Pajahan.

\subsection{Tujuan Penelitian}

1. Untuk mengetahui persepsi masyarakat terhadap dampak sosial pengolahan kopi robusta BUMDes Tugu Sari di Desa Pajahan.

2. Untuk mengetahui dampak ekonomi pengolahan kopi robusta BUMDes Tugu Sari di Desa Pajahan.

3. Untuk mengetahui persepsi masyarakat terhadap dampak pengolahan kopi robusta BUMDes Tugu Sarii di Desa Pajahan.

\section{Metode Penelitian}

\subsection{Lokasi dan Waktu Penelitian}

Penelitian ini dilaksanakan di Desa Pajahan, Kecamatan Pupuan, Kabupaten Tabanan. Alasan pemilihan lokasi penelitian yaitu: 1) Desa Pajahan memiliki lembaga BUMDes yang berusaha mengoptimalkan potensi desa sebagai penghasil kopi robusta dan 2) ketertarikan penulis mempelajari lembaga sosial ekonomi pengembang komoditi kopi secara swadaya, berbasis ekonomi kerakyatan dan pembangunan berkelanjutan. Penelitian dilaksanakan selama satu bulan dari pertengahan bulan November sampai dengan pertengahan bulan Desember 2017.

\subsection{Data, Sampel Penelitian dan Analisis Data}

Data yang dihimpun dalam penelitian ini adalah data kuantitatif dan kualitatif. Data kuantitatif merupakan data yang berwujud angka yaitu upah tenaga kerja, PAD Pajahan yang bersumber dari BUMDes, biaya kontribusi BUMDes terhadap kegiatan desa, pengeluaran BUMDesuntuk pembayaran produk petani penyedia bahan baku dan pengeluaran petani penyedia bahan baku.Data kualitatif merupakan hasil wawancara melalui kuisioner untuk mendeskripsikan persepsi masyarakat terhadap dampak sosial dan lingkungan BUMDes Tugu Sari Pajahan. Data kualitatif juga bersumber dari wawancara mendalam kepada informan kunci yang dipilih secara sengaja (purposive).

Metode yang digunakan untuk pengumpulan data primer dalam penelitian ini adalah wawancara melalui kuisioner dan wawancara mendalam pada informan kunci. Penyebaran kuisioner dilaksanakan pada 43 responden untuk menghimpun persepsi masyarakat terhadap dampak BUMDes. Informan kunci untuk wawancara mendalam yaitu;I Ketut Madi Arsana selaku kepala Desa Pajahan, Sang Made Arsana selaku ketua (kelian) Subak Abian dan Made Marsudi Cahyadi selaku ketua BUMDes Tugu Sari Pajahan. 
Analisis pada penelitian ini adalah analisis deskriptif kualitatif dan kuantitatif. Analisis deskriptif kualitatif untuk mendeskripsikan data persepsi masyarakat Desa Pajahan mengenai dampak sosial dan lingkungan.Pelaksanaan identifikasi data persepsi masyarakat melalui skala likert dengan memberikan lima alternatif pilihan skor pada setiap parameter secara berurutan yaitu 1 (berdampak sangat baik) sampai dengan 5 (berdampak sangat buruk). Perhitungananalisis kuantitatif untuk menganalisis dampak ekonomi dari pengolahan kopi robusta pada BUMDes dengan menggunakan pendekatan economyc impact analysis.

Parameter untuk menilai persepsi masyarakat terhadap dampak sosial adalah hasil kombinasi antara parameter Fachlevi (2015) dan Roswaty (2013). Jumlah parameter adalah sembilan yaitu: 1) kebermanfaatan, 2) akses pasar, 3) pemotongan rantai pasar, 4) pemerataan pembangunan, 5) penyediaan lapangan pekerjaan, 6) upaya memperkecil kesenjangan, 7) peningkatan wawasan masyarakat, 8) kepercayaan masyarakat terhadap kepengurusan BUMDes, 9) kriminalitas, 10) kebudayaan (adat, istiadat dan norma budaya), 11) perubahan gaya hidup masyarakat, dan 12) peningkatan eksistensi desa. Hasil identifikasi selanjutnya diinterprestasikan secara deskriptif dengan instrumen pendukung.

Economyc impact analysisadalah alat identifikasi dampak ekonomi yang terdiri dari dampak langsung (direct impact), dampak tidak langsung (indirect impact) dan dampak imbas (induced impact). Plumstead (2012) mengemukakan bahwa economics impact analysis dapat dimodelkan dengan persamaan matematis sebagai berikut:

$\begin{array}{ll}\text { Direct impact } & : \mathrm{a}+\mathrm{b}+\mathrm{c} . \\ \text { Indirect impact } & : \mathrm{d}+\mathrm{e} \ldots \ldots . . . \\ \text { Induced impact } & : \mathrm{f}+\mathrm{g} \ldots \ldots . . .\end{array}$

Keterangan :

a : PAD Pajahanyang bersumber dari kegiatan pengolahan kopi robusta

BUMDes Tugu Sari Pajahan.

b : Upah yang diberikan BUMDes kepada tenaga kerja lokal.

c : Kontribusi dana bantuan BUMDes terhadap kegiatan masyarakat Desa Pajahan.

$\mathrm{d}$ : Penerimaan petani penyedia bahan baku yang bersumber dari BUMDes.

e : Penerimaan tenaga kerja lokal petani penyedia bahan baku yang bersumber dari petani.

$\mathrm{f}$ : Pengeluaran tenaga kerja BUMDes secara lokal.

$\mathrm{g}$ : Pengeluaran petani penyedia bahan baku secara lokal.

Data tersebut sebagai data awal untuk mengukur dampak pengganda dari arus uang secara lokal (keynesian local multiplier effect). Keynesian local multiplier diartikan sebagai nilai yang menunjukan seberapa besar pengeluaran BUMDes yang berdampak pada peningkatan pendapatan masyarakat lokal, secara matematis dapat dirumuskan sebagai berikut (Armstrong dan Taylor dalam Fachveli, 2012): 
Keynesian local multiplier: $\frac{\mathrm{D}+\mathrm{N}+\mathrm{U}}{\mathrm{E}}$

Keterangan:

E: Pengeluaran BUMDes terhadap masyarakat lokal (rupiah).

D: Dampak langsung dari E (rupiah).

$\mathrm{N}$ : Dampak tidak langsung dari E (rupiah).

U: Dampak lanjutan/imbas dari E (rupiah).

Nilai keynesian local multiplier memiliki kriteria-kriteria sebagai berikut:

1. Apabila hasil perhitungan kurang dari atau sama dengan nol $(\leq 0)$, maka pengolahan kopi robusta BUMDes Tugu Sari belum mampu memberikan dampak ekonomi terhadap masyarakat.

2.Apabila hasil dari perhitungan diantara angka nol dan satu (> $0-<1)$, makapengolahan kopi robusta BUMDes Tugu Sari masih memiliki dampak ekonomi yang rendah terhadap masyarakat.

3.Apabila hasil dari perhitungan lebih besar atau sama dengan satu $(\geq 1)$, maka kegiatan pengolahan kopi robusta BUMDes Tugu Sari telah mampu memberikan dampak ekonomi terhadap masyarakat.

Identifikasi dampak lingkungan dari pengolahan kopi robusta pada BUMDes Tugu Sari juga menggunakan metode yang sama dengan analisis dampak sosial yaitu skala likert yang mendeskripsikan secara kualitatif dengan alternatif skor dampak sangat baik (1) sampai berdampak sangat buruk (5). Parameter yang digunakan untuk menginterpretasikan persepsi masyarakat terhadap dampak lingkungan dalam penelitian ini adalah: 1) dampak terhadap kebersihan desa, 2) dampak terhadap kualitas udara desa, 3) dampak terhadap kualitas air desa, 4) dampak terhadap kebisingan akibat penggunaan mesin kopi, 5) dampak terhadap optimalisasi penggunaan lahan, 6) dampak terhadap peningkatan suber daya alam, 7) dampak terhadap kesehatan masyarakat 8) dampak terhadap penggunaan bahan organik pada budidaya kopi, dan 9) dampak terhadap usaha penurunan bahan kimia sintetis pada budidaya kopi di Desa Pajahan.

\section{Hasil dan Pembahasan}

\subsection{Persepsi Masyarakat terhadap Dampak Sosial}

Keberadaan pengolahan kopi robusta BUMDes Tugu Sari di Desa Pajahan akan menimbulkan berbagai persepsi masyarakat terkait dampak sosial yang dihasilkan. Hasil survei pada 43 responden terdapat berbagai persepsi dengan tingkat penilaian yang berbeda terhadap 12 parameter dampak sosial (tabel 1). Pelaksanaan pengukuran melalui lima alternatif nilai, yaitu 1) sangat baik, 2) baik, 3) tidak berdampak, 4) buruk, dan 5) sangat buruk. Hasil penelitian menunjukan bahwa tidak terdapat persepsi masyarakat yang menilai BUMDes menghasilkan dampak buruk/sangat buruk. Masyarakat Desa Pajahan menganggap bahwa dampak sosial dari pengolahan kopi robusta BUMDes Tugu Sari cenderung baik. 
Tabel 1

Persentase Persepsi Masyarakat Terhadap Dampak Sosial

\begin{tabular}{clccccc}
\hline \multirow{2}{*}{ No. } & & \multicolumn{5}{c}{ Persepsi } \\
\cline { 3 - 7 } & & $\mathbf{1}$ & $\mathbf{2}$ & $\mathbf{3}$ & $\mathbf{4}$ & $\mathbf{5}$ \\
\hline 1 & Kebermanfaatan BUMDes & $49 \%$ & $51 \%$ & - & - & - \\
2 & Akses pasar kopi & $16 \%$ & $84 \%$ & - & - & - \\
3 & Pemotongan rantai pasar & $7 \%$ & $70 \%$ & $23 \%$ & - & - \\
4 & Pemerataan pembangunan & $5 \%$ & $65 \%$ & $30 \%$ & - & - \\
5 & Penyediaan lapangan pekerjaan & $39 \%$ & $61 \%$ & - & - & - \\
6 & Memperkecil kesenjangan sosial & $9 \%$ & $61 \%$ & $30 \%$ & - & - \\
7 & Peningkatan wawasan masyarakat & $21 \%$ & $70 \%$ & $9 \%$ & - & - \\
8 & Kepercayaan masyarakat & $56 \%$ & $44 \%$ & - & - & - \\
9 & Kriminalitas & $5 \%$ & $46 \%$ & $49 \%$ & - & - \\
10 & Kebudayaan & $37 \%$ & $47 \%$ & $16 \%$ & - & - \\
11 & Perubahan gaya hidup masyarakat & $7 \%$ & $67 \%$ & $26 \%$ & - & - \\
12 & Peningkatan eksistensi desa & $47 \%$ & $53 \%$ & - & - & - \\
\hline
\end{tabular}

Sumber: Analisis data primer (2018)

\subsection{Dampak Ekonomi}

Lahirnya BUMDes sebagai badan usaha yang mengelola potensi desa dapat menimbulkan dampak baik atau buruk dalam aspek ekonomi. Penelitian ini hanya menganalisis dampak ekonomi lokal di Desa Pajahan dengan indikator dampak ekonomi langsung, dampak ekonomi tidak langsung dan dampak ekonomi imbas. Menurut Fachlevi (2015), dampak ekonomi langsung adalah penerimaan masyarakat secara langsung dari perusahaan. Dampak ekonomi tidak langsung adalah penerimaan masyarakat secara tidak langsung dari perusahaan. Dampak ekonomi imbas adalah penerimaan masyarakat akibat imbas kegiatan perusahaan.

\subsubsection{Dampak ekonomi langsung (direct impact)}

Hasil penelitian menunjukan bahwa total nilai dampak ekonomi langsung BUMDes secara lokal adalah sebesar Rp5.483.083 per bulan. Rangkuman dampak ekonomi langsung pada tabel 2memperlihatkan bahwa dampak ekonomi langsung terbesar dari kegiatan BUMDes adalah upah tenaga kerja yang mencapai 98,5\%. Dampak ekonomi langsung berdasarkan kontribusi dana bantuan BUMDes terhadap kegiatan di lokasi penelitian hanya $1,5 \%$.

Tabel 2

Dampak Ekonomi Langsung (Direct Impact)

\begin{tabular}{clrr}
\hline No. Keterangan & \multicolumn{1}{c}{$\begin{array}{c}\text { Jumlah } \\
(\text { Rp./Bulan) }\end{array}$} & $\begin{array}{r}\text { Persentase } \\
(\%)\end{array}$ \\
\hline 1 & Upah dari BUMDes kepada tenaga kerja. & 5.400 .000 & 98,5 \\
2 & $\begin{array}{l}\text { Kontribusi dana bantuan BUMDes terhadap } \\
\text { kegiatan di lokasi penelitian. }\end{array}$ & 83.083 & 1,5 \\
\hline & Total & 5.483 .083 & 100,00 \\
\hline
\end{tabular}

Sumber: Analisis data primer (2018) 


\subsubsection{Dampak ekonomi tidak langsung (indirect impact)}

Identifikasi dampak ekonomi tidak langsung berdasarkan pendapatan petani kopi robusta sebagai penyedia bahan baku BUMDes. Hasil penelitian menunjukan rata-rata pendapatan petani kopi robusta yang berasal dari BUMDes adalah Rp246.486/bulan dari total pendapatan seluruh petani Rp9.120.000/bulan. Penelitian ini tidak memperlihatkan dampak ekonomi tidak langsung tenaga kerja petani penyedia bahan baku, karena petani penyedia bahan baku BUMDes adalah petani yang memiliki lahan kurang dari $1 \mathrm{Ha}$ (mengolah lahan sendiri). Total dampak ekonomi tidak langsung BUMDes Tugu Sari Pajahan adalah sebesar Rp9.120.000/bulan.

\subsubsection{Dampak ekonomi imbas (induced impact)}

Dampak ekonomi imbas dalam penelitian ini terdiri dari pengeluaran tenaga kerja BUMDes Tugu Sari dan pengeluaran petani kopi robusta penyedia bahan baku. Perhitungan dampak ekonomi imbas dalam penelitian ini tidak memperhitungkan pengeluaran tenaga kerja petani penyedia bahan baku karena petani penyedia bahan baku BUMDes adalah petani yang memiliki lahan dibawah 1 Ha (mengolah lahannya sendiri). Asumsinyaadalahtidak terdapat dampak ekonomi imbas BUMDes yang bersumber dari tenaga kerja petani penyedia bahan baku di Desa Pajahan.

\section{Tabel 3}

Dampak Ekonomi Imbas (Induced impact)

\begin{tabular}{clrr}
\hline No. & \multicolumn{1}{c}{ Keterangan } & \multicolumn{1}{c}{$\begin{array}{c}\text { Jumlah } \\
\text { (Rp./bulan) }\end{array}$} & $\begin{array}{c}\text { Persentase } \\
(\boldsymbol{\%})\end{array}$ \\
\hline 1 & Pengeluaran tenaga kerja BUMDes & 4.356 .000 & 83,70 \\
2 & Pengeluaran petani penyedia bahan baku & 848.440 & 16,30 \\
\hline & Total & 5.204 .440 & 100,00 \\
\hline
\end{tabular}

Sumber: Analisis data primer (2018)

Tabel 3diatas mendeskripsikan bahwa total dampak ekonomi imbas BUMDes adalah sebesar Rp5.104.440/bulan. Dampak ekonomi imbas tersebut terdiri dari pengeluaran tenaga kerja BUMDes sebesar Rp4.356.000 (83,70\%) dan pengeluaran petani penyedia bahan baku sebesar Rp848.440 (16,30\%). Hasil perhitungan menunjukan bahwa dampak ekonomi imbas dominan bersumber dari pengeluaran tenaga kerja BUMDes Tugu Sari.

\subsubsection{Dampak ekonomi total}

Dampak ekonomi total dari kegiatan BUMDes Tugu Sari Pajahan terdiri dari dampak ekonomi langsung, dampak ekonomi tidak langsung dan dampak ekonomi imbas yang diukur dengan efek pengganda (multiplier effect) arus uang. Keynessian local multipler effect merupakan pendekatan dalam mengukur arus uang yang beredar secara lokal (Fachlevi, 2015). Jumlah uang yang beredar dari kegiatan BUMDes Tugu Saridapat dilihat padatabel 4. 


\section{Tabel 4}

Jumlah Uang yang Beredar Per Bulan Pada Tahun 2017

\begin{tabular}{clr}
\hline No. & \multicolumn{1}{c}{ Keterangan } & Jumlah (Rp.) \\
\hline 1 & (E) Pengeluaran BUMDes terhadap masyarakat lokal & 14.603 .083 \\
2 & (D) Dampak langsung dari E & 5.483 .083 \\
3 & (N) Dampak tidak langsungdari E & 9.120 .000 \\
4 & (U) Dampak imbas dari E & 5.204 .440 \\
\hline
\end{tabular}

Sumber: Analisis Data Primer (2018)

Jumlah uang yang beredar merupakan total uang yang dikeluarkan BUMDes Tugu Sari untuk operasional pengolahan kopi robusta dan kontribusi untuk kegiatankegiatan masyarakat. Jumlah uang beredar yang dikeluarkan BUMDesTugu Sari terdiri dari upah yang diberikan kepada tenaga kerja, kontribusi bantuan dana terhadap kegiatan masyarakat desa dan nominal yang diberiakan untuk membayar bahan baku kepada petani penyedia bahan baku. Total dari uang beredar akibat pengeluaran BUMDes terhadap masyarakat lokal adalah Rp14.603.083/bulan.

Hasil dampak ekonomi secara lokal tersebut digunakan sebagai data awal untuk mengukur dampak pengganda dari arus uang secara lokal (keynesian local multiplier effect) akibat dari kegiatan pengolahan kopi robusta pada BUMDes Tugu Sari. Total nilai dampak ekonomi lokal dibagi dengan pengeluaran BUMDes Tugu Sari untuk masyarakat lokal sehingga mendapatkan nilai keynesian local multiplier effect dengan perhitungan sebagai berikut.

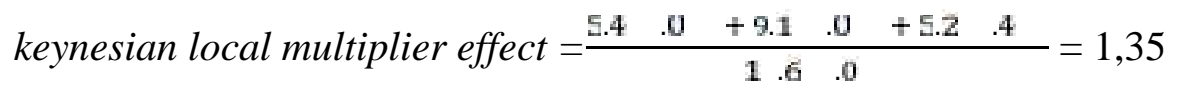

Perhitungan diatas menghasilkan nilai keynesian local multiplier effectsebesar 1,35. Jika nilai hasil perhitungankeynesian local multiplier effectlebih besar atau sama dengan satu $(\geq 1)$, maka kegiatan perusahaan tersebut telah mampu memberikan dampak ekonomi terhadap masyarakat lokal.Kesimpulannya adalah pengolahan kopi robusta BUMDes Tugu Sari telah mampu memberikan dampak ekonomi kepada masyarakat lokal Desa Pajahan.

\subsection{Persepsi Masyarakat terhadap Dampak Lingkungan}

Berikut adalah hasil penilaian masyarakat terhadap sembilan parameter dampak lingkungan yang ditimbulkan oleh BUMDes Tugu Sari Pajahan (tabel 5). Sama halnya dengan dampak sosial, pengukuran juga dilakukan dengan lima alternatif nilai yaitu 1) sangat baik, 2) baik, 3) tidak berdampak, 4) buruk, dan 5) sangat buruk. Hasil menunjukan persepsi masyarakat terhadap dampak lingkungan BUMDes Tugu Sari cenderung baik. Akan tetapi terdapat responden yang memberikan penilaian buruk dan sangat buruk pada parameter dampak kebisingan. Responden yang memiliki persepsi negatif berargumen bahwa kebisingan bersumber dari suara mesin pengolahan kopi BUMDes dan mengganggu proses belajar pada SD Negeri 2 Pajahan. Lokasi BUMDes yang tepat bersebelahan dengan SD Negeri 2 Pajahan mengakibatkan suara mesin pengolahan kopi di BUMDes sangat terdengar dari SD tersebut. 
Tabel 5

Persentase Persepsi Masyarakat Terhadap Dampak Sosial

\begin{tabular}{clccccc}
\hline \multirow{2}{*}{ No. Parameter } & & \multicolumn{5}{c}{ Persepsi } \\
\cline { 3 - 7 } & & $\mathbf{1}$ & $\mathbf{2}$ & $\mathbf{3}$ & $\mathbf{4}$ & $\mathbf{5}$ \\
\hline 1 & Kebersihan & $30 \%$ & $49 \%$ & $21 \%$ & - & - \\
2 & Kualitas udara desa & - & $60 \%$ & $40 \%$ & - & - \\
3 & Kualitas air & - & $47 \%$ & $53 \%$ & - & - \\
4 & Kebisingan & - & - & $76 \%$ & $12 \%$ & $12 \%$ \\
5 & Optimalisasi penggunaan lahan & $5 \%$ & $60 \%$ & $35 \%$ & - & - \\
6 & Peningkatan nilai sumber daya alam & $16 \%$ & $68 \%$ & $16 \%$ & - & - \\
7 & Kesehatan masyarakat & - & $56 \%$ & $44 \%$ & - & - \\
8 & Penggunaan bahan organik & $14 \%$ & $42 \%$ & $44 \%$ & - & - \\
9 & Penurunan penggunaan bahan kimia & $2 \%$ & $44 \%$ & $54 \%$ & - & - \\
& sintetis & & & & &
\end{tabular}

Sumber: analisis data primer (2018)

\section{Simpulan dan Saran}

\subsection{Simpulan}

1. Masyarakat Desa Pajahan menilai bahwa dampak sosial BUMDes Tugu Sari dalam kategori baik.

2. Kegiatan BUMDes Tugu Sari telah mampu memberikan dampak ekonomi terhadap masyarakat lokal Desa Pajahan dengan nilai multiplier effect sebesar 1,35. Dampak ekonomi langsung dari kegiatan BUMDes Tugu Sari adalah sebesar Rp5.483.083/bulan, dampak ekonomi tidak langsung sebesar Rp9.120.000/bulan,dan dampak ekonomi imbas sebesar Rp5.204.440/bulan.

3. Masyarakat Desa Pajahan juga menilai dampak lingkungan BUMDes Tugu Sari dalam kategori baik, akan tetapi kegiatan BUMDes juga menimbulkan dampak buruk/sangat buruk terkait dengan kebisingan suara mesin pengolahan kopi yang mengganggu proses belajar mengajar di SDN Negeri 2 Pajahan.

\subsection{Saran}

1. BUMDes Tugu Sari harusmempertahankan dampak sosial terhadap masyarakat Desa Pajahan.

2. BUMDes Tugu Sari agar senantiasa mempertimbangkan dampak ekonomi terhadap masyarakat termasuk kontribusi dalam peningkatan PAD Pajahan.

3. BUMDes Tugu Sari harus mempertimbangkan lokasi mesin pengolahan kopi agar tidak menimbulkan dampak kebisingan yang dapat mengganggu proses belajar mengajar di SDN Negeri 2 Pajahan.

4. Pemerintah Kabupaten Tabanan dan Provinsi Bali harus mendukung dan memfasilitasi pengembangan BUMDes Tugu Sari. Dukungan terhadap fasilitas bangunan untuk pengolahan kopi sangat strategis diberikan agar BUMDes Tugu Sari mampu berproduksi maksimal tanpa menimbulkan dampak buruk terhadap lingkungan sekitar. 
5. Pemerintah Desa Pajahan dapat mengarahkan BUMDes Tugu Sari untuk membangun kerjasama dengan instansi lain seperti LPD, Koperasi, maupun investor swasta.

6. BUMDes Tugu Sari dapat memperluas pasar melalui optimalisasi digitalisasi teknologi seperti start up lapak online, media sosial dan memanfaatkan jasa ekspedisi pengiriman barang.

7. Dampingan dan/atau kajian terhadap quality control juga penting untuk dilakukan guna menjaga kualitas produksi kopi bubuk BUMDes Tugu Sari.

\section{Ucapan Terimakasih}

Penulis mengucapkan terimakasih kepada: 1) Bapak I Ketut adi Arsana selaku Kepala Desa Pajahan yang telah memberikan informasi gambaran umum Desa Pajahan dan sejarah berdirinya BUMDes, 2) Bapak Made Marsudi Cahyadi selaku ketua BUMDes Tugu Sari Pajahan yang senantiasa mendukung selama penelitian berlangsung dan 3) Bapak Sang Made Arsana selaku kelian (ketua) subak abian Desa Pajahan yang telah memberikan informasi terkait petani kopi robusta di Desa Pajahan sehinggatersusun dalam bentuk jurnal ini.

\section{Daftar Pustaka}

Budiasa. 2011. Pertanian Berkelanjutan \& Teori Permodelan, Denpasar: Udayana University Press.

Fachlevi. 2015. Dampak Pertambangan Batubara Terhadap Ekonomi Lingkungan dan Sosial di Kecamatan Meureubo Kabupaten Aceh Barat.IPB Repsitory.

Kemenperin. 2016. Perkembangan Ekspor Indonesia Berdasarkan Sektor, http://kemenperin.go.id/statistik/peran.php?ekspor=1, diunduh tanggal 27 Mei 2017.

Kementan. 2016. Outlook Kopi Komoditas Pertanian Subsektor Perkebunan, Pusat data dan Sistem Informasi Pertanian Sekretariat Jenderal - Kementrian Pertanian 2016, ISSN: 1907-1507.

MPIG Kopi Robusta Pupuan. 2016. Buku Persyaratan Pendaftaran Indikasi Geografis Kopi Robusta Pupuan Tabanan Bali.

Nasrul. 2012. Pengembangan Lembaga Pertanian untuk Peningkatan Kapasitas Petani terhadap Pembangunan Pertanian, Menara Ilmu, Vol. III, No. 29, Juni 2012.

Plumstead. 2012. Economyc Impact Analysis, 2012 Americas School of Mines-pwc

Roswaty. 2013. Aspek Ekonomi dan Sosial, student.uigm.ac.id, diunduh tanggal 10 Desember 2017.

Sadono. 2008. Pemberdayaan Petani: Paradigma Baru Penyuluh Pertanian di Indonesia, Jurnal Penyuluhan SN: 1858-2664, Vol. 4, No. 1, Maret 2008.

Suradisastra. 2008. Farmer's Intitutional Empowerment Strategy,Forum Penelitian Agro Ekonomi, Vol. 26, No. 2, Desember 2008. 